\title{
Potências animadas do traço: fixidez e animação da caricatura no humor gráfico
}

////////////////// $:$ Benjamim Picado ${ }^{1}$

\section{Jessica Neri ${ }^{2}$}

1. Doutor em comunicação e semiótica pela Pontifícia Universidade Católica de São Paulo e professor do Departamento de Estudos Culturais e Mídia e do Programa de Pós-Graduação em Comunicação da Universidade Federal Fluminense. E-mail: jbpicado@hotmail.com

2. Graduada em jornalismo pela Universidade Federal da Bahia e mestranda do Programa de Pós-Graduação em Comunicação da UFF. E-mail: jessa.nene@gmail.com 


\section{Resumo}

Este artigo pretende examinar certos aspectos das relações entre o desenho e a representação de ações, a partir de um exame sobre tirinhas diárias. Estamos especialmente preocupados com a complementaridade entre os traços estilísticos da caricatura e a questão da compreensão sobre a animação potencial de sua apresentação plástica. Trabalhada a partir do sentido de mudança e de expressividade de seus motivos, a representação fisionômica na caricatura cumpre funções preparatórias para os regimes de significação narrativa na arte sequencial. Numa tal perspectiva, a morfologia dos caracteres do humor gráfico seria mais bem explanada se sua graça cômica fosse considerada como parte do problema geral de um estilo "lacunar" ou "expressivo" da caricatura.

\section{Palavras-chave}

caricatura, comicidade, humor gráfico

\section{Abstract}

This paper examines certain aspects of the relationship between drawing and the representation of actions, studying daily strips. We are particularly concerned with the complementarity between stylistic lines of caricature and the question of understanding the potential animation of its plastic presentation. Analyzed from the sense of change and expressiveness of his motives, the physiognomic representation in caricature accomplishes preparatory functions for the systems of narrative meaning in sequential art. In this perspective, the morphology of the characters of the graphic humor would be better explained if their comic grace is considered as part of the general problem of an "incomplete" or "expressive" style of caricature.

\section{Keywords}

caricature, humor, graphic humor 
A relação entre quadrinhos e humor é bastante antiga - sendo mesmo anterior ao surgimento da chamada indústria das comics, nos últimos anos do século XIX. Antes do surgimento das primeiras tiras cômicas, esse aspecto da comicidade visual já estava bem estabelecido em toda uma tradição da ilustração humorística circulante em publicações impressas, no decorrer do ottocento. A base dessa relação entre a ilustração visual e o humor e os quadrinhos se manifesta em primeira instância nas funções atribuídas à caricatura. $\mathrm{O}$ caráter desse segmento da arte do desenho, seja na forma das charges únicas, seja na matriz sequencial das tiras diárias, faz parte de uma economia textual associada à construção de personagens. Seja como for, o efeito primeiro da caricatura é o de uma síntese de aspectos do reconhecimento visual, reduzindo a iconografia das personagens a seus traços mais expressivos para produzir adequação ao universo narrativo no qual a personagem está inserida.

Podemos restituir os fundamentos do que caracteriza a arte do desenho nos quadrinhos de modo mais denso àquilo que faz o sucesso de um estilo como o da caricatura: sabemos que esse gênero da representação fisionômica consolidou-se na modernidade de tal modo a não nos fazer perceber o quanto ele deve a uma certa transformação dos princípios do retrato, na arte do desenho do século XVIII; é precisamente nessa relação da caricatura com a economia da sobrecarga plástica na expressão pictórica do desenho moderno que nos parece descortinarem-se as linhas gerais nas quais os quadrinhos se desenvolverão (do século seguinte até aqui), não 
apenas como matriz de desenho mas sobretudo como projeto de uma discursividade narrativa, através de formas visuais (GUBERN, 1989). Certos historiadores da arte, por exemplo, não negligenciam esse vínculo entre a arte caricatural e o ethos do desenho barroco: o que os unifica é, de um lado, a comunicação mais instantânea com o espectador e, de outro, a promoção de um sentido de animação das formas visuais sobre o qual o desenho construíra uma plataforma para o desenvolvimento de formas narrativas derivadas.

Em alguns de seus textos, o historiador da arte E. H. Gombrich destaca o modo como a arte do retrato implica aspectos de nossa compreensão das figuras da representação que têm mais a ver com a vivacidade da fisionomia do que com a impressão de realidade que o retrato nos propicia: isso quer dizer que, em face de uma imagem do rosto de quem quer que seja, estamos mais aptos a trabalhar seu reconhecimento na globalidade de sua expressão do que na especificação dos traços definidores de seu reconhecimento. Esse aspecto do retrato é precisamente aquele sobre o qual a caricatura vai operar, no sentido de estabelecer os princípios pelos quais o reconhecimento de seus modelos tornase possível. Há algo que une o retrato mais realista e a caricatura mais grotesca e que se explicita no âmbito daquilo que estamos prontos a reconhecer na representação fisionômica, em geral, isto é: a vívida animação de sua apresentação, o que é explicitado por nosso modo mesmo de reagir a uma fisionomia.

Reagimos a um rosto como um todo: vemos uma face como digna, ansiosa, triste ou sardônica muito antes de sermos capazes de explicar que traços ou relações são responsáveis por esta impressão intuitiva. Duvido que jamais sejamos capazes de dizer exatamente que mudanças fazem com que um rosto se ilumine num sorriso ou se enevoe numa expressão pensativa simplesmente pela observação das pessoas que se agitam a nossa volta. Porque [...] o que nos é dado é a impressão global e a nossa reação a ela; na verdade, vemos distâncias e não alterações de tamanho; vemos "realmente" a luz e não as modificações de matiz; e, sobretudo, o que vemos na verdade é uma face mais aberta, mais alegre, e não um abrandamento das expressões musculares (GOMBRICH, 1995, p. 355). 
Examinemos essas questões, agora à luz de exemplos como os que estão abaixo (Figuras 1 e 2). Interessa-nos identificar nestes casos de uma arte da sátira visual os aspectos que fazem a questão do efeito humorístico do traço derivar dessa economia experiencial de nossa relação com a fisionomia e com o modo como o desenho é capaz de operar com ela. Em nossa perspectiva de análise, a caricatura deve ser abordada numa dúplice função de operador de reconhecimento e índice de uma narratividade que atravessa a plasticidade do desenho.

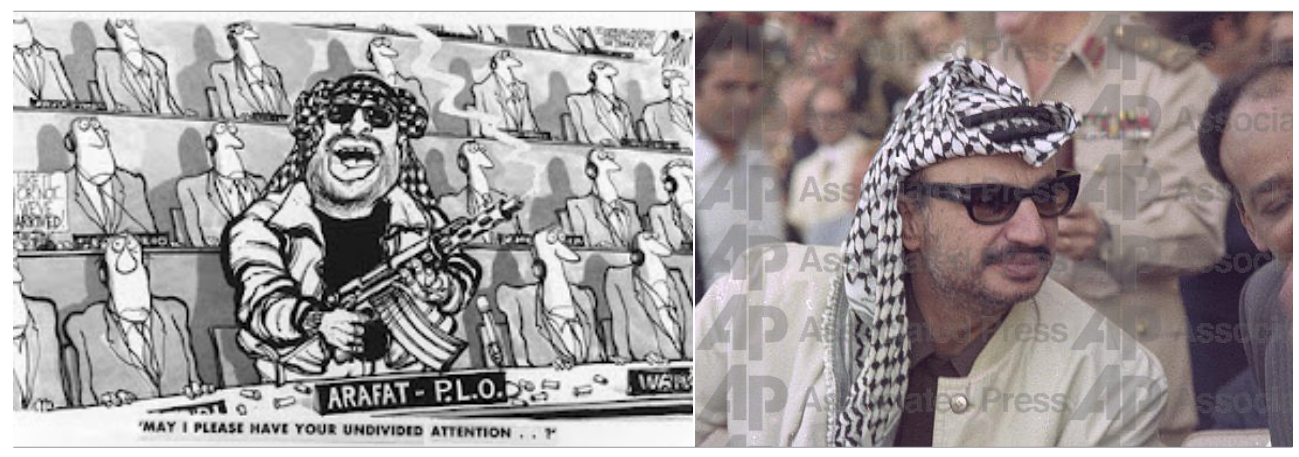

Figura 1: Patrick Oliphant

- Yasser Arafat (1974)

Figura 2: Yasser Arafat - Associated Press (1974)
Procuremos examinar esses casos, naquilo que transparece deles, para além das questões relativas à singularidade estilística da caricatura, em cada um: em todas essas imagens, prevalece uma espécie de matriz anamórfica da representação da fisionomia, constituída como uma regra de ouro da caricatura; isso significa que a possibilidade de reconhecimento das personagens públicas decorre da inscrição de sua apresentação a uma circunstância precisa de sua expressividade. As feições características que a caricatura vai operar como modelo de suas transformações se enraízam em um aspecto originário da expressão fisionômica, o que fica mais patente quando examinamos esses traços em comparação com a expressividade originária de seus personagens, em retratos mais realistas.

Para além do fato de ser esse procedimento o que caracteriza mais fortemente a orientação das matrizes plásticas da caricatura para a produção da comicidade (sendo a anamorfose que define, 
inclusive, a maior parte daquilo que caracteriza esse gênero da representação pictórica na modernidade), nosso interesse recai, sobretudo, nas questões relativas ao modo como sua plasticidade favorece os regimes de discursividade que se alinham ao desenho, a partir daí. Nesse contexto, a hipérbole plástica que supostamente definiria a caricatura é, para nós, apenas mais uma das variantes da produção do efeito próprio ao humor gráfico. Nesses termos, são os princípios da modificação da forma visual e dos traços da individuação (moral, psicológica, política) do modelo que entram em jogo, na maneira como o humor se produz efetivamente no desenho, na especial perspectiva do trabalho sobre sua plasticidade.

Mesmo se pensarmos exclusivamente no caso da caricatura de personalidades e na função que ela preenche - de um comentário sobre a vida social e política -, podemos notar o quão pouco rentável é supor que sua eficácia, enquanto forma do desenho, derive apenas dos critérios representacionais pelos quais pode ser definida: é evidente, de um lado, que a possibilidade de reconhecimento dos modelos representados é um elemento importante de seu efeito, mas podemos nos perguntar se a comicidade que lhe é própria tem algo a ver com esse seu caráter estritamente representacional, de maneira mais exclusiva. É nesse sentido, inclusive, que Gombrich evoca tantas vezes a questão da caricatura, no contexto do exame sobre certos fenômenos psicológicos associados à representação pictórica. No caso da representação fisionômica, o sucesso da caricatura deve-se menos ao fato de que podemos reconhecer seus modelos e mais ao modo como ela mobiliza algumas capacidades projetivas da forma reconhecível, originárias da percepção comum.

No caso da caricatura, o desenhista trabalha precisamente sobre as características do modelo que são opostas àquelas que interessam ao retrato realista. Assim sendo, não são os aspectos mais permanentes da fisionomia do modelo que importam ao caricaturista, mas aqueles que derivam da modificação momentânea dessa disposição mais fixa do caráter; nesses termos, podemos reconhecer que a captura da fisionomia, em sua dimensão de momentânea e variante expressividade (mais própria ao modo como o rosto é capturado num segmento de uma ação qualquer: num bocejo, num sorriso ou 
num ataque de fúria, por exemplo), é o centro de interesses mais importante da arte da caricatura, sobretudo naquilo que respeita seu propósito de colocar o reconhecimento e a fixação do caráter como objetivos da representação fisionômica.

\footnotetext{
Pense no topete de Napoleão e naquele seu gesto de ficar em pé, com a mão enfiada em seu casaco, que sabe-se que o ator Talma teria sugerido a ele. Isto funcionou como uma dádiva dos deuses para os imitadores e cartunistas, que buscavam uma fórmula para representar as aspirações napoleônicas - e o mesmo truque valeu para os Napoleões menores que tivemos que aturar (GOMBRICH, 1982, p. 112).
}

Precisamente nesse ponto, emergem as questões que nos interessam, na discussão das relações entre a arte do retrato e a rendição do movimento na representação fisionômica da caricatura: em termos, o "roubo" de um segmento da expressividade fisionômica nos permite repensar as relações entre a caricatura e o retrato, na medida em que possibilita recolocar em jogo a questão das condicionantes propriamente perceptivas do reconhecimento fisionômico. A fixidez com a qual os motivos são apresentados na caricatura é sempre capaz de expor os aspectos vívidos (portanto dinâmicos) de seu caráter, porque a imagem entra em relação com a faculdade projetiva da experiência perceptiva, que tende a complementar os aspectos que o embargo da imagem propicia às funções dinâmicas da expressão fisionômica. É nesse sentido que podemos identificar, inclusive, os aspectos que coligam a arte da caricatura a um princípio anamórfico da representação fisionômica: os diferentes estados da expressão corporal e da facial e a mudança de caráter do retratado que eles indicam constitui, nesses casos, o centro das atenções do trabalho do desenhista.

Desse modo, a exploração da caricatura tem de estar integrada a uma forma de pensar os aspectos referenciais da figuração pictórica de modo a incluí-la no contexto das ações representadas por meio do desenho: deve-se considerar, portanto, o âmbito da assimilação das formas visuais aos princípios poéticos da composição de poemas dramáticos, dos quais a comédia é claramente uma das manifestações. Fica claro aqui como se integram metodologicamente - em nossa 
análise dos regimes plástico-discursivos quadrinísticos - a síntese entre o problema das estruturas icônicas do traço no desenho e a produção do sentido textual ao qual as representações ficarão doravante vinculadas, decorrendo daí a complementaridade que assume para nós o recurso às disciplinas da interpretação textual e às ciências da arte (em especial, a poética e a estética).

Assim sendo, um primeiro aspecto a destacar no humor gráfico diz respeito aos princípios plásticos da caracterização dos actantes que habitam suas tramas narrativas: o traço caricatural se destaca nessa variante dos quadrinhos de muitos modos, dos quais destacamos, sobretudo, dois: em primeiro lugar, na esteira de uma tradição coeva a essa origem, a predominância do traço simples se define como uma tendência da representação pictórica nessa altura do século XIX; assim sendo, o desenho humorístico prolonga uma tradição das artes pictóricas desse mesmo período, primando pela simplicidade do traço e pela exageração plástica que visa o comentário humorado sobre personalidades e atualidades de várias espécies.

Esse modo de tratar o aspecto iconicamente lacunar do traço caricatural está, para diversos autores, na base daquilo que promove um segundo aspecto do humor gráfico, aquele que o define como uma ocorrência do gênero da "figuração narrativa" (MOLITERNI, 1967). Nesses termos, já observamos como a exploração da caricatura deve estar integrada a um modo de pensar os aspectos referenciais da figuração pictórica que nos permitiria ampliar suas funções até o ponto de vê-las funcionando como parte de um contexto das ações - é nesse aspecto que a questão da comicidade assume o caráter de uma questão que se pode lançar a uma poética do desenho de humor. Isso nos leva a propor um exame do desenho na caricatura, em seus aspectos de promoção do movimento ou da particular circunstância das ações em que seus personagens estão eventualmente integrados: nossa atenção se volta especialmente para o tratamento da forma expressiva do traço e das funções que ela pode cumprir para favorecer esse efeito plástico de dinamização das formas visuais. 
outra $[\ldots]$ organizando-se em uma verdadeira narrativa que ultrapassa o quadro de uma simples gag, a partir de um tema fundamental, na qual as manifestações humorísticas constituem variações cotidianas, este sendo frequentemente o caso de Peanuts, de Schulz (MOLITERNI, 1967, p. 199).

Nos comentários breves que faz em seus três famosos ensaios sobre a significação da comicidade, Henri Bergson destaca a questão de um aspecto expressivo que a fisionomia própria ao humor cômico precisa manifestar, de modo a evocar em nós o quadro das paixões correspondentes ao gênero cômico: esse problema está associado ao que é necessário reforçar na fisionomia, de modo a nela identificar não um mal que acomete o corpo, tampouco um traço da feiúra, mas aquilo que é próprio da expressividade fisionômica - o aspecto risível da distorção fisionômica teria um correlato nos modos de fazer perceber nos traços exagerados de sua apresentação a indicação de um movimento do espírito, inscrito no rosto da personagem cômica.

Para que o exagero seja cômico, é necessário que ele não apareça como o objetivo, mas como um meio simples que o desenhador usa para manifestar aos nossos olhos as contorções que ele vê prepararem-se na natureza. É essa distorção que importa, é ela que interessa. E é por isso que buscaremos nos elementos da fisionomia que são incapazes de movimento, na curva de um nariz e mesmo sob a forma de uma orelha. É que a forma é para nós o esboço de um movimento (BERGSON, 1924, p. 19).

Nas escolas formalistas da história da arte (que fazem quase desaparecer as diferenças entre as tarefas das diferentes disciplinas que compõem o campo das ciências da arte, como a história da pintura e a estética), essa questão do estilo do desenho se demarca pelo característico ponto de inflexão que diferencia, por exemplo, o traço de Dürer do de Rembrandt. Separados por não mais que um século e meio, os limites estilísticos entre esses dois pintores exemplificam aquilo que Heinrich Wölfflin identificou como sendo a transformação mais importante na história da arte ocidental: a saber, aquela que demarca na pintura o final do classicismo e os prenúncios da modernidade, sinalizados pelo estilo barroco. 
Essa passagem é sinalizada pela famosa clivagem que Wölfflin propõe entre um estilo "linear" (próprio a Dürer) e um "pictórico" (característico de Rembrandt): quando resume essas ideias, ele identifica esse prenúncio de uma arte barroca no modo como o sentido de mudança se inscreve nas formas visuais - vibração particular que retira essas formas da sua condição inerte e permanente e que faz o quadro jogar com um contexto mais dinâmico das ações. Esses efeitos não são notáveis apenas na pintura mas também no desenho; considerando, mais uma vez, as diferenças propriamente estilísticas entre Dürer e Rembrandt no âmbito do traço, Wölfflin reitera as diferenças entre a valorização dos contornos - no primeiro caso - e a dos volumes e das massas - no último. Examinando de perto o problema da representação da fisionomia no estilo pictórico do desenho, ele examina um retrato do poeta Jan Vos, feito pelo pintor holandês Jan Lievens contemporâneo de Rembrandt - , valorizando nele os aspectos do preenchimento do contorno, mais do que o das linhas, atribuindo ao resultado da composição um efeito de instabilidade da forma, resultante do tratamento incompleto das linhas.

A expressão desapareceu por completo dos contornos e repousa nas partes internas da forma. Dois olhos escuros, de expressão viva, um leve estremecimento dos lábios; aqui e acolá aparece uma linha, que volta a desaparecer logo em seguida. Os longos traços do estilo linear estão completamente ausentes. Segmentos isolados de linhas definem a forma da boca, alguns traços interrompidos dão forma aos olhos e às sobrancelhas. Por vezes o desenho é completamente interrompido. As sombras modeladoras já não possuem validade objetiva. Entretanto, no tratamento do contorno da fronte e do queixo, tudo é feito para impedir que a forma evolua para uma silhueta, ou seja, para excluir a hipótese de ela ser apreendida em linhas (WÖLFFLIN, 1996, p. 51).

Esse trabalho sobre o dinamismo da forma do traço e do desenho introduz, de maneira decisiva, a matriz através da qual podemos avaliar a produção da comicidade, enquanto função associada ao trabalho sobre as formas visuais e sobre sua potencial animação. Do ponto de vista de sua gênese histórica, a caricatura e o humor que lhe é inerente são oriundos desse quadro, no qual as características 
representacionais do desenho ficam submetidas a um estilo que investe sobre a comunicação de uma mudança que se percebe nos objetos da figuração pictórica. É mediante tal valorização de uma potência animada do traço - característica do estilo pictórico na arte do desenho, a partir do século XVII - que se poderia explicar esse arco inteiro ao qual a caricatura se encontraria assimilada, enquanto gênero da figuração narrativa; o modo como sua materialidade plástica serve aos propósitos da animação das formas visuais é a chave com a qual podemos compreender as funções que o desenho passará a cumprir, enquanto elemento de uma discursividade, próprio ao comentário satírico ou próprio às pequenas narrativas humoradas das tirinhas diárias.

Outro aspecto importante da definição da personagem cômica presente em narrativas gráficas diz respeito ao programa de efeitos ao qual o desenho está submetido, mas que precisa ser analisado numa esfera outra que não a da estrita plasticidade do traço caricatural: o estilo abreviado do desenho de humor está constitutivamente subordinado às peculiaridades do efeito próprio a uma poética da comicidade. Na perspectiva em que Bergson aborda o fenômeno do riso e suas relações com o gênero cômico, ele identifica sua essência com um aspecto da mecanização da vida. Segundo ele, o caráter humano é, por natureza, dinâmico, e o cômico advém do engessamento desse dinamismo, da quebra do fluxo, da instauração de uma lógica mecânica ao caráter humano.

Um homem que corria na rua tropeça e cai: os transeuntes riem. Não riríamos dele, penso eu, se pudéssemos supor que veio a ele, de repente, a ideia de se sentar no chão. Ri-se do fato de que ele sentouse involuntariamente. Não é sua súbita mudança de atitude que nos faz rir, é aquilo que há aí de involuntário na mudança, é a falta de jeito. Uma pedra estaria talvez no caminho. Ele teria sido obrigado a mudar de direção ou desviar-se do obstáculo. Mas, por falta de flexibilidade, por distração ou obstinação do corpo, por um efeito de rigidez ou da velocidade do movimento, seus músculos continuaram a executar o movimento, mesmo quando as circunstâncias exigiam uma outra coisa. É por isso que o homem está caindo, e é disso que riem os transeuntes (BERGSON, 1924, p. 12). 
Ao transpor esses aspectos da significação da comicidade para a caracterização do personagem cômico, Bergson afirma que "rimo-nos sempre que uma pessoa nos dê a impressão de ser uma coisa”. Porém, o riso pressupõe uma ressalva: o não envolvimento emocional do espectador. Esse afastamento emocional é viabilizado pelo afastamento da personagem cômica daquilo que é humano através da mecanização. A personagem cômica é, antes de mais nada, um tipo, conclui Bergson:

Em certo sentido, poder-se-ia dizer que todo caráter é cômico, desde que se entenda por caráter o que há de já feito em nossa pessoa, e que está em nós em estado de mecanismo montado, capaz de funcionar automaticamente. Será aquilo pelo que nos repetimos. E será também, por conseguinte, aquilo pelo que outros nos poderão imitar. O personagem cômico é um tipo. Inversamente, a semelhança a um tipo tem qualquer coisa de cômico (BERGSON, 1924, p. 65).

Esse caráter de tipo das personagens cômicas concebidas graficamente manifesta-se exatamente através da caricatura; porém, aqui estamos falando de um estilo caricatural que visa o riso. A caricatura, na condição de representação gráfica de traços marcantes que permitem fácil reconhecimento, é dotada dessa inelasticidade mencionada por Bergson. Seu efeito primeiro é o de produzir um automatismo da identificação, transformando a expressividade do representado em algo mecânico. O que torna a caricatura cômica é sua fixidez, é a redução da expressão humana a poucos traços que dão conta de uma personalidade. Esses poucos traços, no entanto, sintetizam aquilo que caracteriza a personagem. No caso da personagem cômica apresentada nos quadrinhos, além de um tipo caricatural, ela é também um tipo cômico, e esse tipo duplo - por assim dizer - apresenta determinadas características que o distinguem de outros estilos caricaturais.

Pintar caracteres, ou seja, tipos gerais; aí está portanto o objeto da alta comédia. Já dissemos isso muitas vezes. Mas queremos repeti-lo, pois estimamos que essa fórmula seja suficiente para definir a comédia. Não apenas, com efeito, a comédia nos apresenta tipos gerais, mas é a única das artes que, em nossa opinião, visa o geral, de modo que, 


\begin{abstract}
assim que nós subscrevemos nela essa tarefa, dizemos aquilo que ela é e aquilo que as restantes artes não podem ser. Para provar que tal é a essência da comédia e que ela se opõe, por isso mesmo, à tragédia, ao drama e às outras formas de arte, seria necessário definir a arte naquilo que ela tem de mais elevado: então, ao descermos pouco a pouco até a poesia cômica, veríamos que ela está posta nos confins da arte e da vida e que ela se recorta, por seu caráter de generalidade, do restante das artes (BERGSON, 1924, p. 65-66).
\end{abstract}

Dentre aqueles que pensaram mais nuclearmente sobre as relações entre o traço caricatural e suas virtudes narrativas, é certamente o semiólogo Harry Morgan aquele que nos aporta algumas das intuições mais interessantes a esse respeito: em sua perspectiva de análise, são os aspectos do desenho caricatural - em suas dimensões técnica e semiótica - que oferecem aos quadrinhos certos parâmetros básicos para o desenvolvimento de sua narratividade mais própria. Segundo ele, a porta de entrada no universo narrativo se dá através do modo como as personagens são pensadas, através de suas características visuais, sintetizadas por um estilo do traço que muito se aproxima da economia gráfica da caricatura, muito embora cumpram nos quadrinhos funções de reconhecimento bastante próprias.

Se o desenho único da charge se orienta predominantemente pelas regras do gênero do retrato pictórico (e condensação icônica de seus caracteres definidores), no caso dos quadrinhos, é o princípio técnico da "autotipia" que orienta a produção do desenho, no que respeita a definição e a possibilidade de reconhecimento de seus actantes: em se tratando de uma forma visual pautada pela replicação do traço definidor das personagens, nos diferentes segmentos da narrativa em que estes últimos serão encontrados, os caracteres da ação devem ser construídos a partir de uma determinada síntese inicial de seus aspectos mais proeminentes. Destaque-se mais uma vez que essa síntese não pode ser confundida com aquela que caracteriza a economia pictórica do retrato, pois sua finalidade é a de oferecer as condições básicas de legibilidade da trama, no contexto da propagação do desenho, na sequencialidade das tiras. Morgan salienta que, além de uma estratégia narrativa, 
há um fator mercadológico que explica esse estilo do traço estabelecido no universo dos quadrinhos. A simplicidade desse traço e a consequente transformação das personagens em tipos serviam à necessidade de um sistema de produção em série que fosse obrigatoriamente rápido e de fácil reprodução: pode-se dizer que essa é uma regra que se sedimenta fundamentalmente na arte dos quadrinhos do século XX.

Todos esses personagens devem ser reduzidos a alguns traços mínimos, de modo a serem compreendidos à primeira vista. Por outro lado, se examinarmos certas tirinhas do século XIX, notaremos que o leitor moderno pode ter problemas em identificá-los, precisamente porque faltam ao herói as características marcantes ou porque de uma imagem para outra há diferenças de caráter. O desenho é muito mais intrincado do que ele é numa tirinha do século XX, mas tal complexidade vem às custas de um sentido mais claro de caracterização (MORGAN, 2009, p. 24).

Em sua reflexão sobre o estilo caricatural, Gombrich recupera algumas passagens do tratado sobre fisiognomonia do desenhista suíço Rudolph Töpffer, reconhecido como um dos precursores dos quadrinhos. Em seu pequeno tratado, Töpffer afirma que o desenho linear (simplificado) é puro simbolismo (convenção) e que o artista que trabalha o estilo abreviatório pode sempre contar com o observador para suplementar aquilo que omitiu. Nesse sentido, as expressões elípticas são lidas como partes da narrativa e representam uma intenção autoral. No caso da personagem gráfica cômica, aquilo que é omitido é o que a personagem não é: tudo o que ela representa e é capaz de desenvolver encontra-se em sua construção. A caricatura cômica em narrativas ficcionais utiliza-se do aspecto fixo do traço caricatural para construir seus tipos. Nesse caso, as expressões elípticas mencionadas por Töpffer seriam aquilo que tornaria essas personagens dinâmicas em sua construção, mas aî estas últimas perderiam o aspecto mecânico que as torna cômicas, segundo a definição de Bergson.

Mas haveria - ainda sobre o tratado de Töpffer - um segundo aspecto definidor do desenho de caráter, em seu aspecto 
de construção narrativa. Gombrich destaca a distinção que o artista suíço faz entre os traços permanentes e não permanentes da fisionomia humana, assim como sobre os modos como a representação pictórica pode tirar partido deles. Na medida em que os traços permanentes estariam ligados à comunicação instantânea do caráter, enquanto os não permanentes se conectariam à compreensão das emoções vividas pelos sujeitos, podemos especular sobre como o estilo abreviado da caricatura também implicaria uma valorização da expressividade constitutiva dos aspectos não permanentes da fisionomia: aquilo a que Töpffer visava era segundo Gombrich - uma definição das chaves iconográficas mínimas da expressividade fisionômica humana.

O mais surpreendente com relação a essas chaves da expressão é, sem dúvida, que elas transformam quase toda forma na semelhança do ser vivo. É só descobrir a expressão no olho fixo ou na boca aberta de uma forma inanimada, e aquilo que se poderia chamar de "lei de Töpffer" entra em ação - a forma não será classificada apenas como uma faca, mas vai adquirir caráter e expressão, vai ser dotada de vida, de uma presença. Se é que existe uma hierarquia de chaves às quais reagimos instintivamente, a expressão é um trunfo em relação à luz (GOMBRICH, 1995, p. 363).

Esse aspecto da economia plástica do desenho de humor, ressaltado por Gombrich em sua análise das chaves expressivas de Töpffer, reverbera um outro fator da abreviatura do traço na arte dos quadrinhos, destacada por Morgan: a saber, a "rapidez da execução" do desenho caricato. Se a "autotipia", de que tratamos mais acima, se define como a variável mais técnica desse gênero do desenho, a rapidez caracteriza um aspecto mais semiótico dessa iconografia. Sob tal ângulo de observação, poderíamos dizer que as personagens cômicas gráficas são exploradas a partir da fixação de um traço variável da expressão, que resultará num modelo da caracterização que favorece nossas estruturas de reação à expressividade fisionômica, ao mesmo tempo que gera as figuras mais próximas do caráter mecânico e autotípico da significação cômica, como a concebe Bergson. 
Tal caracterização coincide com a que Umberto Eco identifica num primeiro momento histórico do traço caricatural, que antecede a chamada caricatura moderna. Na sua Storia della bruttezza, Eco enfatiza que esse momento é geralmente representado pelos retratos grotescos de Leonardo da Vinci, que diferem da caricatura moderna por construírem tipos “inventados”, em vez de criar tipos a partir de expoentes da sociedade vigente. Segundo Eco, representações desse tipo antecediam inclusive o trabalho de Leonardo, com a construção de tipos de caráter deformado e engessado, tais como "o diabo", "o ladrão" etc.

Já a caricatura moderna, afirma o autor, nasce polêmica, com o caráter de crítica social a figuras de poder. Esse estilo caricatural caracteriza-se pela exageração deformadora (de um traço físico ou psicológico do indivíduo), cujo objetivo é depreciar o representado. A construção tipificada característica do momento anterior coincide com a caracterização das personagens cômicas gráficas no que tange ao engessamento do caráter, à redução a uma única expressão. Um aspecto importante de suas relações com um certo discurso moral é o de que, podendo manifestar um sentido de comicidade ou de sátira social, elas nem sempre são inspiradas pelo propósito da ridicularização de seus motivos.

Existem certamente caricaturas voltadas para humilhar e tornar odioso o próprio alvo $[\ldots]$. Contudo, no mais das vezes, a caricatura pretende também, ao enfatizar algumas características do sujeito, alcançar um conhecimento mais profundo de seu caráter. E também não pretende sempre denunciar uma "feiúra" interior, podendo trazer à luz características físicas e intelectuais ou comportamentos que tornam o caricaturado amável e simpático. Assim, enquanto as caricaturas ferozes de Daumier e Grosz denunciam a baixeza moral de certos personagens e tipos de seu tempo, as caricaturas de pensadores e artistas realizadas por Tullio Pericoli são verdadeiros retratos de grande penetração psicológica que muitas vezes atingem a celebração (ECO, 2007, p. 152).

Se pensarmos em duas personagens bastante populares do universo das comic strips, veremos o quão significativa é essa construção mais positiva de um traço caricatural. Charlie Brown (de Peanuts, 
Figura 3: Charlie Brown - Charles Schulz [19--?]

Figura 4: Calvin - Bill Waterson [19--?] de Charles Schulz) e Calvin (de Calvin and Hobbes, de Bill Waterson) são dois garotos que têm mais ou menos a mesma idade (não mais que sete anos), mas que são representados de modo bastante distinto, devido às exigências do contexto narrativo de cada um. Podemos examinar, em cada um deles, como o estilo abreviado do desenho serve ao propósito de definir os caracteres comportamentais mais salientes das personagens, mas também é usado para favorecer a inscrição de ambos a seus respectivos contextos dramáticos de interação física ou verbal (e o fato de que seus efeitos são quase que invariavelmente associados à graça cômica, à produção do riso).

Enquanto Charlie Brown é um garoto melancólico e que se sente fracassado em tudo o que faz (manifestando uma paleta algo restrita de expressões fisionômicas no decorrer de suas “aventuras”), Calvin é, por sua vez, um garoto sarcástico, encrenqueiro e dinâmico (o que acarreta um quadro mais variável de sua apresentação fisionômica). Olhando para Calvin, podemos perceber seu dinamismo através de sua expressão permanentemente vivaz, de seu cabelo espetado e de seus olhos arregalados. Já Charlie Brown possui uma expressão reticente, pouco inspirada, e seus cabelos são tão ralos que ele parece ser calvo, apesar de ser uma criança. Toda a sua construção nos leva a crer que estamos diante de um senhor melancólico, apesar de se tratar apenas de um menino (Figuras 3 e 4 ).
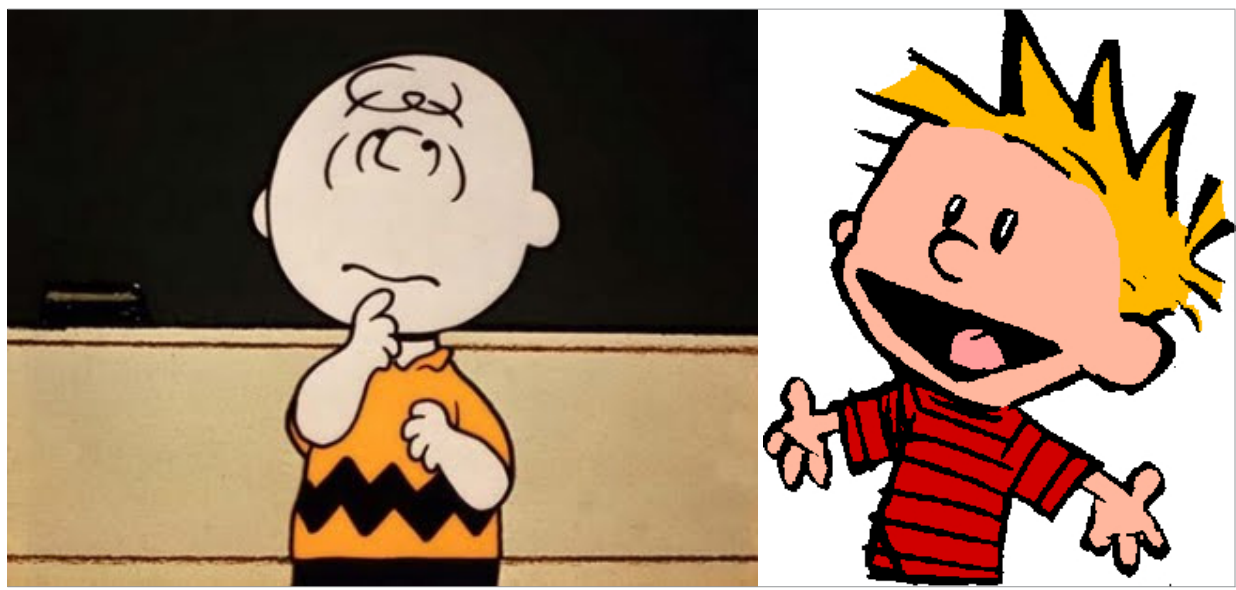
O que torna ambas as personagens cômicas é a condição estática tanto do caráter de Charlie Brown como do de Calvin. Haja o que houver, eles não deixarão de ser quem são: o primeiro, um garoto de alma velha, um eterno perdedor; já o segundo, um garoto encrenqueiro que vive num mundo fantasioso. Essa fixidez na construção da personagem cômica é explicada por Bergson num comparativo com a personagem dramática:

Para distinguir-se dele [o drama], para nos impedir de tomar a sério a ação séria, para nos predispor a rir, ela [a comédia] se vale de um meio cuja fórmula enuncio assim: em vez de concentrar nossa atenção sobre os atos, ela a dirige sobretudo para os gestos. Entendo aqui por gestos as atitudes, os movimentos e mesmo o discurso pelos quais um estado de alma se manifesta sem objetivo, sem proveito, pelo efeito apenas de certa espécie de arrumação interior. $\mathrm{O}$ gesto assim definido difere profundamente da ação. A ação é intencional, ou pelo menos consciente; o gesto escapa, é automático. Na ação, a pessoa empenha-se toda; no gesto, uma parte isolada da pessoa se exprime, à revelia da personalidade total ou pelo menos destacada dela (BERGSON, 1924, p. 63).

A personagem cômica em comic strips está, portanto, restrita a um número reduzido de chaves de expressão e de contextos de ações que, de algum modo, se encontram preparados no modo de sua construção gráfica, na economia iconológica mais própria da caricatura. Essa construção já enfatiza aquilo que Bergson denomina de gesto e predefine suas possibilidades narrativas: há, portanto, um tipo de economia narrativa em tiras cômicas que consiste na construção de um universo de expectativa sobre possíveis piadas a partir da seleção de personagens que compõem a tira. Tal aspecto oferece um diferencial à aplicação da função de leitura que um sistema dos quadrinhos, como aquele proposto por Thierry Groensteen (1999), estipula para os elementos gerais da quadrinização, na sua aplicação mais restrita às tiras cômicas.

Acreditamos que, além disso, a construção gráfico-narrativa das personagens cômicas em comic strips, num quadro mais amplo, dá indicações sobre o estilo de humor predominante nas obras, do ponto de vista das situações e dos esquemas narrativos 
predominantes nessas histórias. Para entender a relação entre esses aspectos, tornar-se-ia necessário integrar o estudo da caricatura (e as funções de dinamização que ela preenche) à estrutura textual da piada, assim como ao modo pelo qual ela se adéqua ao dispositivo espaço-tópico da tira - disso tudo resultando o papel-chave nas etapas da serialização das comic strips. Esse, entretanto, é assunto para outra oportunidade. 


\section{Referências}

BERGSON, H. Le rire: essai sur la signification du comique. Paris: Alcan, 1924.

ECO, U. História da feiúra. Tradução de Eliana Aguiar. Rio: Record, 2007.

GOMBRICH, E. H. Arte e ilusão. Tradução de Raul de Sá Barbosa. São Paulo: Martins Fontes: 1995.

The image and the eye. London: Phaidon, 1982.

GROENSTEEN, T. Système de la bande dessinée. Paris: PUF, 1999.

GUBERN, R. "La narration iconique au moyen des images fixes". Degrés, 59, p. bl-b30, 1989.

MOLITERNI, C. "Technique narrative". In: COUPERIE, P. (Org.). Bande dessinée et figuration narrative. Paris: Musée des Arts Décoratifs: Palais du Louvre, 1967.

MORGAN, H. "Graphic shorthand: from caricature to narratology in twentieth century's bande dessinée and comics". European Comic Art, v. 2, n. 1, p. 21-28, 2009.

WÖLFFLIN, H. Conceitos fundamentais da história da arte. Tradução de João Azenha Jr. São Paulo: Martins Fontes, 1996. 